[Article]

\title{
化学改性氧化石墨烯交联的聚酰亚胺气凝胶
}

\author{
梁 祎 卢 斑武 姚维尚张学同 ${ }^{*}$ \\ (北京理工大学材料科学与工程学院, 北京 100081)
}

\begin{abstract}
摘要: 聚酰亚胺 $(\mathrm{PI})$ 气凝胶是一类密度低、机械性能好、隔热性能优异的多孔材料, 通常使用昂贵的化学交联 剂进行交联. 氧化石墨烯 (GO) 是近年来广受关注的用于聚合物增强的纳米功能填料. 以前报道的 PI/GO 复合 材料多是纤维或膜的形式. 为了获得 PI/GO 复合气凝胶, 本文采用化学改性氧化石墨烯 (m-GO) 替代 1,3,5三(4-氨基苯氧基)苯(TAB)等常规的交联剂, 使之与 4, $4^{\prime}$-二氨基二苯基醚(ODA)和 3,3',4,4'联苯四羧酸二䣶 (BPDA)反应, 制得了 $\mathrm{m}-\mathrm{GO}$ 交联的PI气凝胶. $\mathrm{GO}$ 的化学改性通过其与过量 ODA 在水热条件下反应实现. 通过 扫描电子显微镜(SEM)研究了 $\mathrm{Pl} / \mathrm{m}-\mathrm{GO}$ 气凝胶的微观结构. 分别通过氮气吸脱附测试、热重分析和热线法研究 了 $\mathrm{m}-\mathrm{GO}$ 对气凝胶的孔特性、热稳定性和热导率的影响. 测试结果表明, 所获得的 $\mathrm{Pl} / \mathrm{m}-\mathrm{GO}$ 气凝胶保持了高的 孔隙率、热稳定性和绝热性. 压缩测试结果显示, 与采用 $1.8 \%$ (质量分数, $w$ ) 的 $\mathrm{TAB}$ 进行交联的 PI气凝胶相比, 仅用 $0.6 \%(w)$ 的 m-GO 交联所获得的气凝胶具有更高的比杨氏模量(杨氏模量/密度)、比屈服强度(屈服强度/密 度)和更小的体积收缩率.
\end{abstract}

关键词: 聚酰亚胺气凝胶; 氧化石墨烯; 交联; 机械性能; 收缩率 中图分类号: 0648

\section{Polyimide Aerogels Crosslinked with Chemically Modified Graphene Oxide}

\author{
LIANG Yi LU Yun* YAO Wei-Shang ZHANG Xue-Tong* \\ (School of Materials Science \& Engineering, Beijing Institute of Technology, Beijing 100081, P. R. China)
}

\begin{abstract}
Polyimide (PI) aerogels, which are generally crosslinked using expensive chemical crosslinking agents, are novel porous materials with high strength, high heat resistance, high porosity, and low density. Graphene oxide (GO) is a functional nanofiller that has aroused wide interest in recent years. The reported PI/ GO composites have mostly been in the form of fibers and films. In this study, PI/GO composite aerogels were obtained using chemically modified graphene oxide ( $\mathrm{m}-\mathrm{GO})$ as the crosslinking agent, instead of traditional ones such as 1,3,5-triaminophenoxybenzene (TAB), by reaction with 4,4'-oxydianiline (ODA) and 3,3',4,4'biphenyltetracarboxylic dianhydride (BPDA). The chemical modification of $G O$ was achieved by reacting GO with excess ODA using a hydrothermal method. The microstructures of the $\mathrm{Pl} / \mathrm{m}-\mathrm{GO}$ aerogels were investigated using scanning electron microscopy (SEM). Nitrogen sorption tests, thermogravimetric analysis, and a hot-wire method were used to investigate the effects of $\mathrm{m}-\mathrm{GO}$ on the pore properties, thermal stabilities, and thermal conductivities, respectively, of the resulting aerogels. The results show that the $\mathrm{Pl} / \mathrm{m}-\mathrm{GO}$ aerogels are highly porous, thermally stable, and heat insulating. Compression tests showed that the $\mathrm{PI}$ aerogel prepared using $0.6 \%$ (mass fraction, $w$ ) m-GO instead of $1.8 \%(w)$ TAB as the crosslinking agent had a higher specific Young's modulus [Young's modulus/density $(\rho)]$ and specific yield strength (yield strength/ $\rho$ ), and less shrinkage.
\end{abstract}

Received: December 30, 2014; Revised: April 13, 2015; Published on Web: April 14, 2015.

"Corresponding authors. LU Yun, Email: luyun@bit.edu.cn. ZHANG Xue-Tong, Email: zhangxtchina@yahoo.com; Tel: +86-10-68912370.

The project was supported by the National Natural Science Foundation of China (21373024) and Innovation Program of the Beijing Institute of Technology, China.

国家自然科学基金(21373024)和北京理工大学创新项目基金资助

(c) Editorial office of Acta Physico-Chimica Sinica 
Key Words: Polyimide aerogel; Graphene oxide; Crosslinking; Mechanical property; Shrinkage ratio

\section{Introduction}

Aerogels are ultra-light and highly porous nano-materials assembled by nano-sized building units such as zero-dimensional (0D) nano-particles, one-dimensional (1D) nano-wires, and twodimensional (2D) nano-sheets. Its consecutive open pours endow aerogels with unique properties and potential applications in various fields such as acoustical and thermal insulations, catalysis, etc. Since the first case on $\mathrm{SiO}_{2}$ aerogel was reported in 1931 by Kistler, ${ }^{1}$ many kinds of inorganic and polymeric aerogels have been produced by far. ${ }^{2-6}$ Although aerogels have aroused intense interests all over the world, they are not used as much as it was expected. Besides the unique drying technique, this is ascribed to the fragileness for the most inorganic aerogels and the relatively poor thermal stability for the most polymeric aerogels. For many applications, typically in the fields of aerospace, superior mechanical property and high thermal stability are both needed. In 2004, Rhine et al. ${ }^{7}$ disclosed the preparation of linear polyimide aerogels that composed of aromatic dianhydrides and aromatic diamines or a combined aromatic and aliphatic diamines. However, the three-dimensional (3D) network structures of these linear aerogels are not covalently bonded but produced through the physical interaction between polymer chains. Therefore, although the mechanical property of these aerogels is good, they tend to exhibit a large amount of shrinkage during the fabrication process. To further improve the mechanical property, and to reduce the shrinkage, Meador et al..$^{8-11}$ in National Aeronautics and Space Administration (NASA) has synthesized a series of polyimide (PI) aerogels crosslinked with multifunctional amines such as eight (amino)-silsesquioxane (OAPS) and 1,3,5-triaminophenoxy benzene (TAB). They also applied chemical imidization at room temperature with excess pyridine/acetic anhydride instead of heating imidization to obtain fully imidized aerogels. The crosslinked PI aerogels generally exhibited higher glass transition temperature, better mechanical property, and less amount of shrinkage than linear aerogels. These research results make PI aerogels be potential candidates for aerospace applications.

In this study, we report PI aerogels crosslinked with chemically modified graphene oxides ( $\mathrm{m}-\mathrm{GO}$ ). GO is a sheet-like carbon nano-material with super high Young's modulus due to its unique lattice structure. Bearing carboxyl group, carbonyl groups, epoxy groups, and hydroxyl groups on its basal planes and edges, ${ }^{12,13}$ GO is solvent compatible and chemically active, which makes it a prominent candidate to fabricate high strength and functional resin-based composite. PI/GO composites, exhibiting enhanced mechanical properties, high decomposition temperature and so on, have been extensively studied. ${ }^{14-19}$ However, most reported PI/GO composites were studied in the form of films or fibers rather than aerogels. Investigation on the synthesis of the PI/GO aerogel may provide a clue to develop a novel porous composite. In this article, GO modified with 4,4'-oxydianiline (ODA) was used to crosslink
PI aerogels. The organic amine groups derived from ODA endow the m-GO sheets not only to dissolve better in organic solvents, but also to react with the dianhydride. This may turn out to be an economic method to crosslink the PI aerogel by avoiding the use of expensive traditional crosslinking agents. The effects of $\mathrm{m}-\mathrm{GO}$ on the morphology, pore property, thermal stability, shrinkage, thermal insulation, and mechanical property of the composite aerogels will be investigated.

\section{Experimental}

\subsection{Materials}

4,4'-Oxydianiline (98\%) was purchased from Sinopharm Chemical Reagent Co., Ltd.; $N$-methyl-2-pyrrolidinone (NMP, 99.5\% ) was purchased from Beijing Tongguang Chemical Company. Acetone (99.5\%) was purchased from Beijing Keweinuo Chemical Reagent Co., Ltd.; Pyridine (99\%) was purchased from Beijing Chemical Factory. These reagents were used without further purification. 3,3', 4,4'- Biphenyltetracarboxylic dianhydride (BPDA, 98\%) was purchased from Beijing Zhong Ke Chemical Technology Co. Ltd. and dried at $120^{\circ} \mathrm{C}$ for $24 \mathrm{~h}$ prior to use. GO was synthesized according to the steps reported in our previous study. ${ }^{20} 1,3,5$-Triaminophenoxy benzene (TAB) was prepared according to the procedure reported in the literature. ${ }^{21-23}$

\subsection{Preparation of $\mathrm{m}-\mathrm{GO}$}

The m-GO was prepared approximately according to the method reported in the literature ${ }^{15}$ except that hydrothermal reaction vessel was used to conduct the reaction, which omitting the $24 \mathrm{~h}$ nitrogen purge. Briefly, to $150 \mathrm{~mL} \mathrm{NMP,} 1.5 \mathrm{~g}$ GO was added and ultrasonication was applied to obtain uniform suspension. A solution of $2.3 \mathrm{~g}$ ODA in $15 \mathrm{~mL}$ NMP was added to the GO suspension under stir at $80{ }^{\circ} \mathrm{C}$. Then the mixture was moved into hydrothermal reaction vessel and heated at $80{ }^{\circ} \mathrm{C}$ in oven for 24 h. After the reaction was finished, solvent-exchange was applied in acetone to remove the unreacted ODA. The m-GO powder obtained by filtration was re-dispersed into NMP by ultrasonication. The concentration of $\mathrm{m}-\mathrm{GO}$ in NMP was determined to be $3.5 \mathrm{mg} \cdot \mathrm{mL}^{-1}$.

\subsection{Synthesis of $\mathrm{PI} / \mathrm{m}-\mathrm{GO}$ aerogels}

The PI/m-GO aerogels (PI aerogels crosslinked by m-GO) was synthesized as shown in Fig.S1 (Supporting Information). As an example, the synthesis of the PI/m-GO aerogel with $0.2 \% \mathrm{~m}-\mathrm{GO}$ content is described as follows. To a solution of ODA (1.58 g, 7.9 $\mathrm{mmol}$ ) in $35.8 \mathrm{~mL}$ of NMP, $2.1 \mathrm{~mL}$ concentrated m-GO suspension was added and ultrasonication was applied. After $15 \mathrm{~min}$ of ultrasonication, BPDA (2.395 g, $8.15 \mathrm{mmol})$ was added under nitrogen. Acetic anhydride $(6.15 \mathrm{~mL}, 65 \mathrm{mmol}, 8: 1$ molar ratio to BPDA) and pyridine $(5.25 \mathrm{~mL}, 65 \mathrm{mmol})$ were added under stirring after the BPDA was dissolved. The mixture was poured into mold immediately to form gel. The reaction scheme is shown 
in Fig.S1. The obtained gel was aged for $24 \mathrm{~h}$ at room temperature and then solvent-exchanged with ethanol. After that, the gel was subject to supercritical $\mathrm{CO}_{2}$ extraction. By changing the ratio of $\mathrm{m}-\mathrm{GO}$ suspension to NMP, a series of $\mathrm{PI} / \mathrm{m}-\mathrm{GO}$ aerogels with different $\mathrm{m}$ - GO contents were prepared. For simplicity, these aerogels were named as $\mathrm{PI} / x \% \mathrm{~m}-\mathrm{GO}$, in which $x \%$ refers to the mass fraction of m-GO. A PI aerogel crosslinked with $1.8 \%(w)$ $\mathrm{TAB}$ was prepared as a control sample named as $\mathrm{PI} / 1.8 \% \mathrm{TAB}$. The synthesis of $\mathrm{PI} / 1.8 \% \mathrm{TAB}$ is similar to the $\mathrm{PI} / 0.2 \% \mathrm{~m}-\mathrm{GO}$. ODA (1.58 g, $7.9 \mathrm{mmol})$ and BPDA (2.395 g, $8.15 \mathrm{mmol})$ were dissolved in NMP $(33 \mathrm{~mL})$ under nitrogen atmosphere. Then the solution of TAB $(0.07 \mathrm{~g}, 0.175 \mathrm{mmol})$ in NMP $(5.65 \mathrm{~mL})$ was added and ultrasonication was applied. The subsequent operations were gelation, ageing, solvent exchange, and super critical $\mathrm{CO}_{2}$ drying. All the PI/m-GO composite aerogels and the PI/TAB aerogel were designed with the theoretical density $(\rho)$ of $75 \mathrm{mg} \cdot$ $\mathrm{cm}^{-3}$.

\subsection{Instrumentations}

Microstructure observation was conducted by scanning electron microscope (SEM, Hitachi, S-4800, Japan) with an accelerating voltage of 5-10 kV after sputter coating of the specimens with platinum. Raman spectra (HORIBA Jobin Yvon S. A. S, RAM HR800, France) were recorded with an excitation laser wavelength of $632.8 \mathrm{~nm}$. X-ray powder diffraction (XRD, Rigaku, Dmax 2200, Japan) was conducted with $\mathrm{Cu} K_{\alpha}$ radiation $(\lambda=$ $0.15416 \mathrm{~nm}$ ). Fourier transform infrared (FTIR) spectrum was

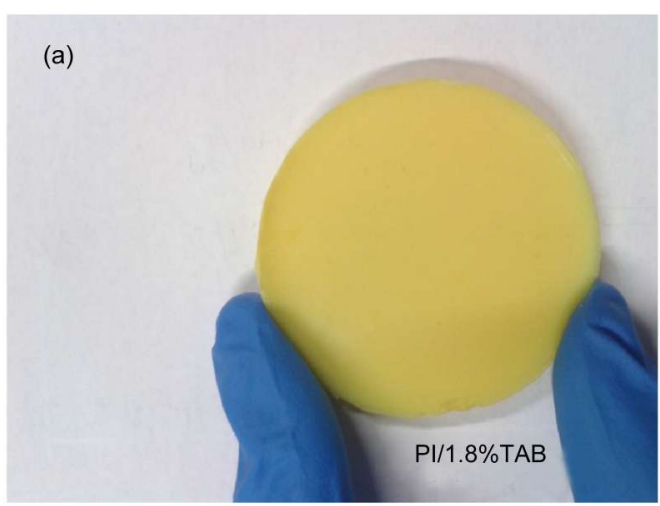

(c)

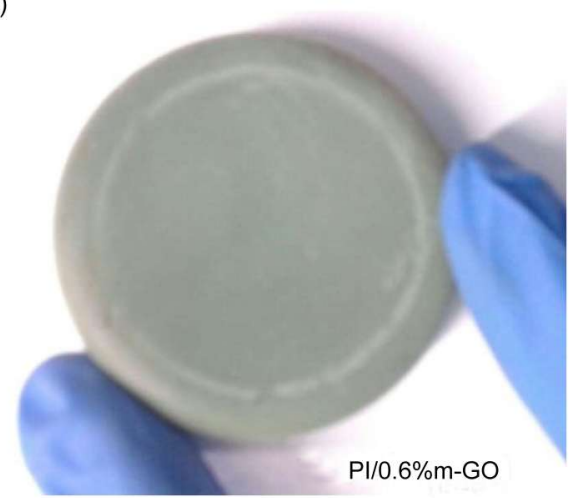

conducted on the Tensor 27 spectroscopy (Bruker Optics, Germany). The X-ray photoelectron spectroscopy spectrograph (XPS, Kratos, AXIS Ultra XPS, Japan) has a monochromatic Al $K_{\alpha}$ radiation $(h v=1486.71 \mathrm{eV})$ powered with $10 \mathrm{~mA}$ and $15 \mathrm{kV}$. Brunauer-Emmett-Teller (BET) nitrogen sorption isotherms were investigated by ASAP 2010 (Micromeritics, America) instrument at $77 \mathrm{~K}$, and the pore size distribution was calculated from the desorption branch of sorption isotherms by the Barrett-JoynerHalenda (BJH) formula. Thermogravimetric (TG) analysis was conducted on a TG209 (Netzsch, Germany) instrument from room temperature to $850{ }^{\circ} \mathrm{C}$ with a heating rate of $10^{\circ} \mathrm{C} \cdot \mathrm{min}^{-1}$ under nitrogen atmosphere. The compression tests were carried on by a universal test machine (6022, America) made in Instron. The compression velocity was $30 \%$ of the sample length per minute and the test would be stopped when the strain reached $80 \%$ of the sample length. The specimens for compression tests were prepared in accordance with ASTM D695-10, in which the sample sizes are nominally $1.5-1.8 \mathrm{~cm}$ in diameter and the length is close to the twice as long as the diameter. Thermal conductivity was taken at room temperature on a thermal conductivity measuring instrument (Xi'an Summer Creek Electronic Technology Co., Ltd., TC 3010L, China) by the hot wire method.

\section{Results and discussion}

The image photos (Fig.S2), Raman spectra (Fig.S3(a)), XRD patterns (Fig.S3(b)), and FTIR spectra (Fig.S4) (Supporting In-
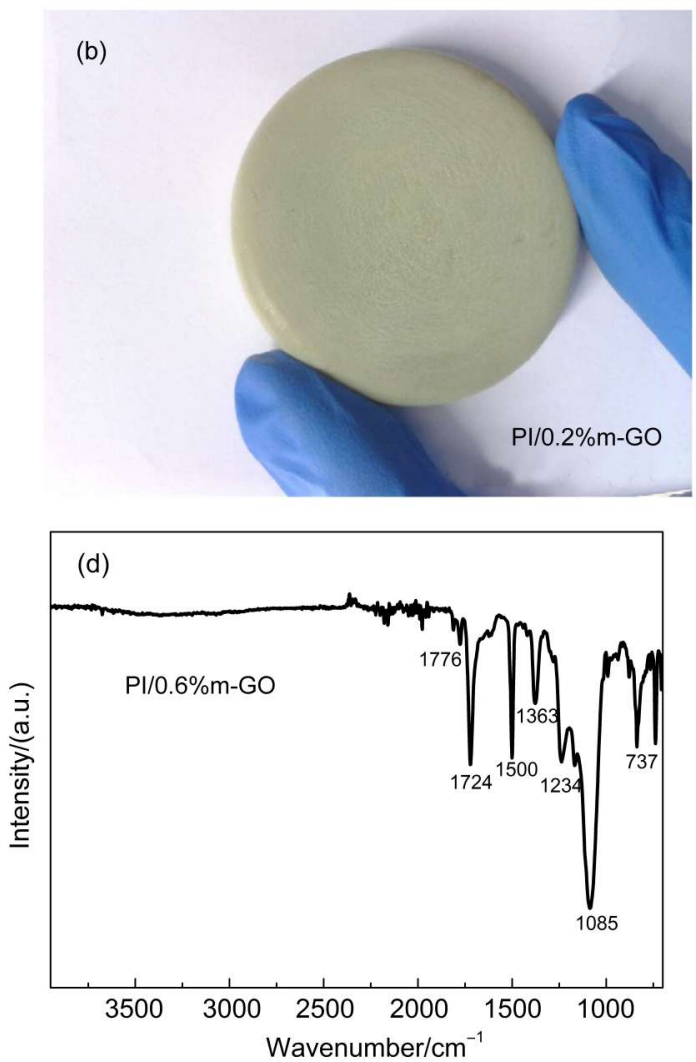

Fig.1 Digital photos of (a) PI/1.8\%TAB aerogel, (b) PI/0.2\%m-GO composite aerogel, (c) PI/0.6\%m-GO composite aerogel, and (d) the FTIR spectrum of PI/m-GO aerogel 
formation) of the obtained $\mathrm{m}-\mathrm{GO}$ were investigated. The results are in accordance with those reported in the literature,$^{15}$ which confirms that the organic amine groups have grafted onto the GO sheet by the reaction of the organic amine with the epoxy of GO. Moreover, differing from the literature, XPS spectra (Fig.S5 (Supporting Information)) show none peak ascribed to carbonyl or carboxyl groups, suggesting that a higher $\mathrm{GO}$ reduction degree $(\mathrm{O} \%=25.2 \%)$ may be achieved by use of the hydrothermal reaction vessel.

To enable the poly(amid acid) (PAA) to react with the $\mathrm{m}-\mathrm{GO}$ or TAB, the PAA was formulated with anhydride as the end group by adjusting the molar ratio of BPDA to ODA to be $(n+1): n$, in which $n$ is the number of repeated units. Eight-fold excess of acetic anhydride and pyridine was used to insure complete chemical imidization. The color of the $\mathrm{PI} / \mathrm{m}-\mathrm{GO}$ composite aerogels is totally different from that of $\mathrm{PI} / 1.8 \% \mathrm{TAB}$ aerogel, and gets darker with the increase of the m-GO content, as shown in Fig.1(a-c). Fig.1(d) shows the FTIR spectrum of the obtained PI/
m-GO aerogel. The absence of bands at $\sim 1800$ and $\sim 1670 \mathrm{~cm}^{-1}$ indicating the existence of isoimide and bands at $3200-3500 \mathrm{~cm}^{-1}$ referring to $-\mathrm{OH}$ indicate that the imidization is complete. ${ }^{24-26}$

To investigate the microstructure of the $\mathrm{PI} / \mathrm{m}-\mathrm{GO}$ aerogel, the SEM was conducted. Fig.2(b-d) shows the SEM photos of the PI/ $\mathrm{m}-\mathrm{GO}$ aerogel at various regions with different magnifications. It can be seen from Fig.2(b) that the m-GO sheets are quite thick and have coarse surface, which is quite different from what they present before reacting with PAA (Fig.S2). Fig.2(c) is the magnified picture of the region within the black circle in Fig.2(b), showing that the coarse surface of m-GO sheet is composed of PI aggregates. This indicates that the PI chains are able to propagate on the $\mathrm{m}-\mathrm{GO}$ sheets by reacting with the amine group on $\mathrm{m}-\mathrm{GO}$. The PI aggregates on m-GO sheets are similar to those composing of PI matrix in the PI/m-GO aerogel (Fig.2(d)), while the former present shorter fibrous shape and more compacting morphology than the latter. The structure of PI parts in the PI/m-GO aerogel shown in Fig.2(d) seems the same as that of the PI/1.8\% TAB
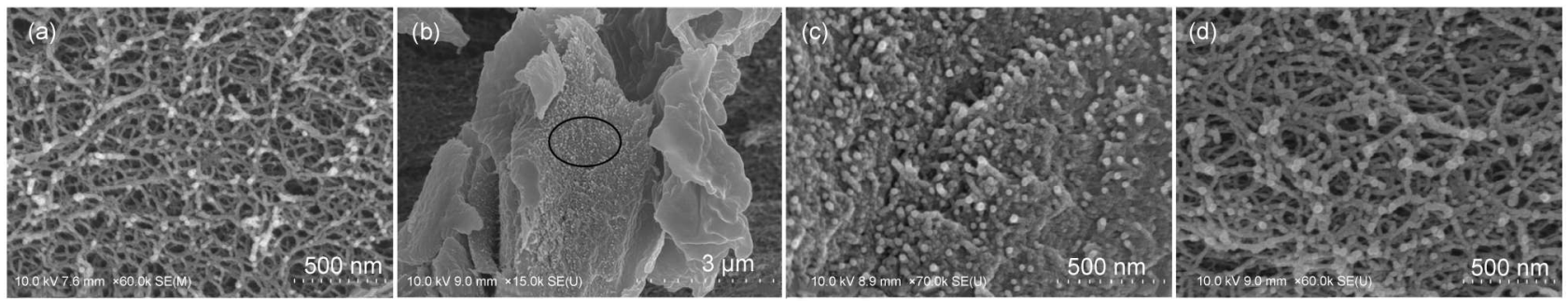

Fig.2 SEM images of (a) PI/1.8\%TAB aerogel and (b-d) PI/m-GO coposite aerogel
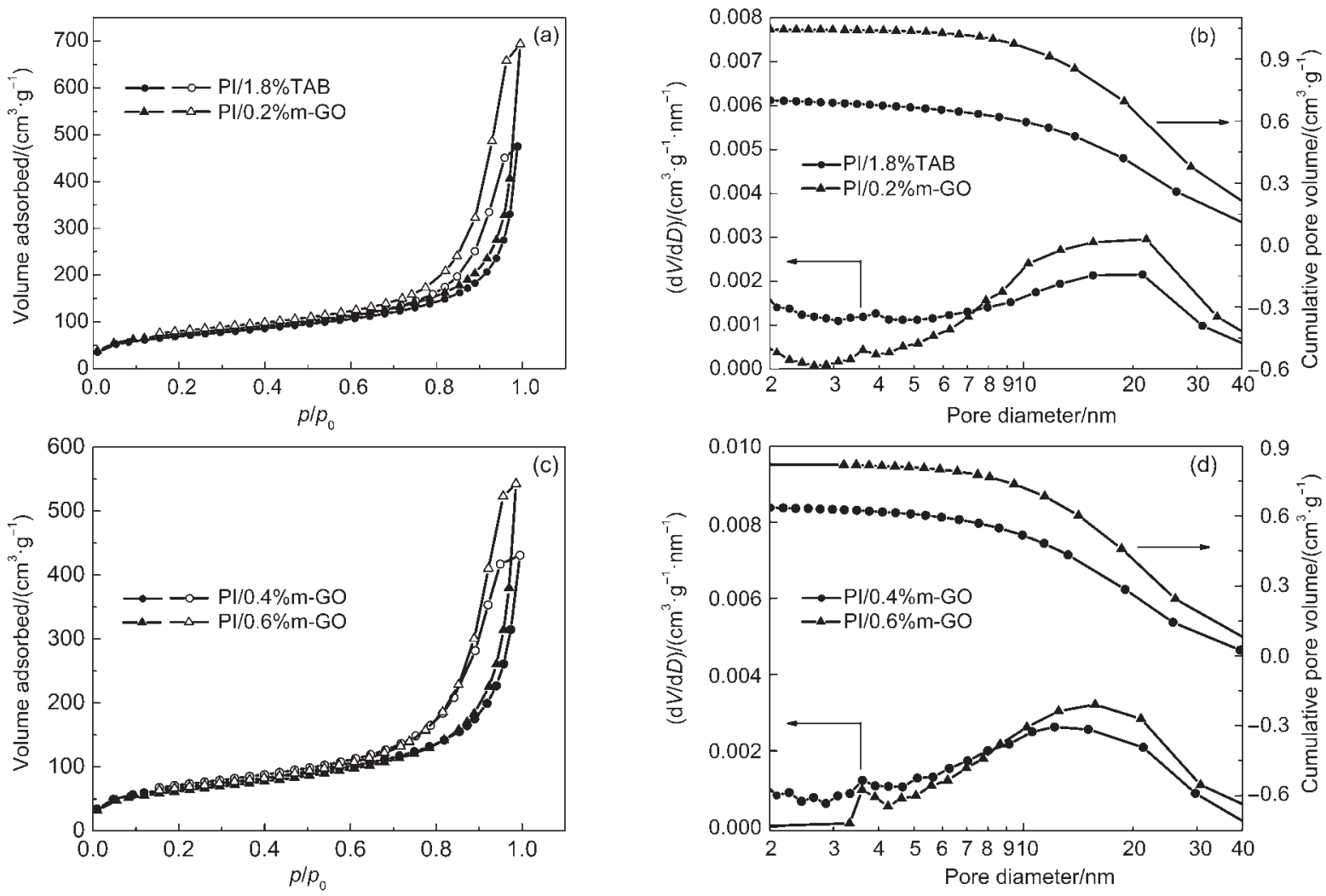

Fig.3 Typical nitrogen adsorption-desorption isotherms $(a, c)$ and pore size distribution $(b, d)$ of the obtained aerogels 
aerogel shown in Fig.2(a), both are porous frameworks composed of tangled fibrous PI aggregates with diameter of about 20 to 30 nm.

Since the m-GO sheets quite differ from the traditional crosslink agents in size, concern of whether this would damage the pore property and mechanical property of the composite aerogels was aroused. Curves of typical nitrogen adsorption-desorption isotherms of the obtained aerogels are shown in Fig.3. The pore structure data of $\mathrm{PI} / \mathrm{m}-\mathrm{GO}$ aerogels listed in Table 1 were calculated by BJH method. According to IUPAC, all the adsorption and desorption curves are type IV isotherms with a H1 hysteresis loop, which indicates that the $\mathrm{PI} / \mathrm{m}-\mathrm{GO}$ aerogels are mesoporous materials. ${ }^{9,27}$ This result is consistent with the average pore diameter of 12.8-18.3 nm recorded in Table 1. It can be seen that the pore property of the $\mathrm{PI} / \mathrm{m}-\mathrm{GO}$ aerogels does not signifucantly distinguish from that of the PI/1.8\%TAB aerogel, and no obvious trend of the pore property relative to $\mathrm{m}-\mathrm{GO}$ content is observed.

Compression tests for the obtained aerogels were performed and the stress-strain curves are shown in Fig.4. The photo inserted in Fig. 4 shows the shape of PI/0.6\%m-GO aerogel before and after compression. The sample did not break during compression, and the radial dimension remained unchanged. Actually, all the composite aerogels acted in the same way, indicating good toughness. All the stress-strain curves present three stages: (1) linear stage, in which the reversible deformation occurred and the slope of the curve was considered as Young's modulus (hereinafter referred to as $E$ ), (2) yield stage, in which the framework of the aerogel began to collapse and irreversible deformation occurred, and (3) dense stage, in which the structure of the aerogel became dense and the stress increased sharply with the developing of

Table 1 Pore structure data of PI/1.8\%TAB and PI/m-GO aerogels with different $\mathrm{m}-\mathrm{GO}$ contents

\begin{tabular}{cccc}
\hline Sample & $\frac{\text { Pore volume }}{\left(\mathrm{cm}^{3} \cdot \mathrm{g}^{-1}\right)}$ & $\begin{array}{c}\text { Average pore } \\
\text { diameter } / \mathrm{nm}\end{array}$ & $\begin{array}{c}\text { BET specific } \\
\text { surface area } /\left(\mathrm{m}^{2} \cdot \mathrm{g}^{-1}\right)\end{array}$ \\
\hline $\mathrm{PI} / 1.8 \% \mathrm{TAB}$ & 0.71 & 13.0 & 239.0 \\
$\mathrm{PI} / 0.2 \% \mathrm{~m}-\mathrm{GO}$ & 1.04 & 18.3 & 259.0 \\
$\mathrm{PI} / 0.4 \% \mathrm{~m}-\mathrm{GO}$ & 0.64 & 12.8 & 232.3 \\
$\mathrm{PI} / 0.6 \% \mathrm{~m}-\mathrm{GO}$ & 0.82 & 16.0 & 218.0 \\
\hline
\end{tabular}

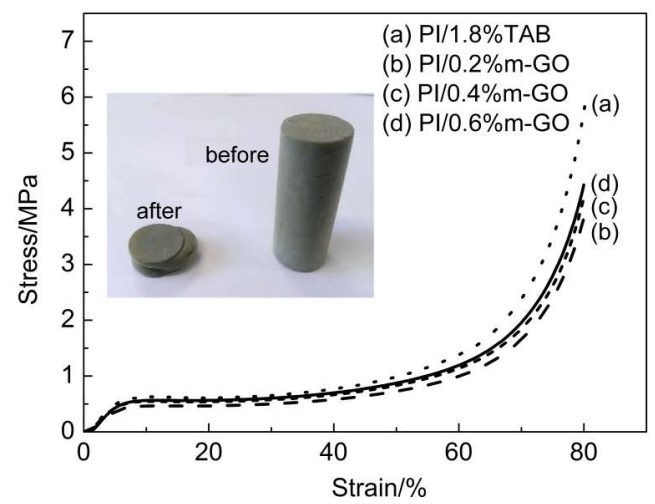

Fig.4 Stress-strain curves of (a) PI/1.8\%TAB, (b) PI/0.2\%mGO, (c) PI/0.4\%m-GO, (d) PI/0.6\%m-GO and the inset showing the shape of $\mathrm{PI} / 0.6 \% \mathrm{~m}-\mathrm{GO}$ aerogel before and after compression strain. Although as mentioned above, all the aerogels were prepared with the theoretical density of $75 \mathrm{mg} \cdot \mathrm{cm}^{-3}$, their actual apparent density $(\rho)$ varied slightly due to the uncontrollable shrinkage. Therefore, to compare their mechanical property appropriately, the concepts of specific Young's modulus $(E / \rho)$ and specific yield strength (yield strength $/ \rho$ ) are used herein. It can be seen in Table 2 that $E$ and yield strength of the $\mathrm{PI} / \mathrm{m}-\mathrm{GO}$ aerogels both enhanced with the increase of the m-GO contents. When the $\mathrm{m}-\mathrm{GO}$ content reached $0.6 \%$, the specific Young's modulus and specific yield strength of the $\mathrm{PI} / \mathrm{m}-\mathrm{GO}$ aerogel were higher than those of PI/1.8\%TAB aerogel. The volume shrinkage ratios of the obtained aerogels were calculated according to the following equation: volume shrinkage $V_{\mathrm{s}}=\left(V_{\text {wet gel }}-V_{\text {aerogel }}\right) / V_{\text {wet gel }} \times 100 \%$. As shown in Fig.5, the amount of shrinkage for $\mathrm{PI} / \mathrm{m}-\mathrm{GO}$ aerogels crosslinked with $0.2 \%-0.6 \% \mathrm{~m}-\mathrm{GO}$ is about $26 \%$, which is less than that of PI aerogel crosslinked with $1.8 \% \mathrm{TAB}(34 \%)$.

GO is a material with good thermal conductivity. The thermal

Table 2 Mechanical data of PI/1.8\%TAB and PI/m-GO aerogels with different $\mathrm{m}-\mathrm{GO}$ contents

\begin{tabular}{|c|c|c|c|c|c|}
\hline Sample & $\frac{\rho}{\left(\mathrm{mg} \cdot \mathrm{cm}^{-3}\right)}$ & $\frac{E}{\mathrm{MPa}}$ & $\frac{(E / \rho)}{\left(\mathrm{J} \cdot \mathrm{g}^{-1}\right)}$ & $\frac{\text { Yeild strength }}{\mathrm{MPa}}$ & $\begin{array}{l}\text { Specific yield } \\
\text { strength } /\left(\mathrm{J} \cdot \mathrm{g}^{-1}\right)\end{array}$ \\
\hline $\mathrm{PI} / 1.8 \% \mathrm{TAB}$ & 126.2 & 13.70 & 108.56 & 0.478 & 3.79 \\
\hline $\mathrm{PI} / 0.2 \% \mathrm{~m}-\mathrm{GO}$ & 116.8 & 10.50 & 89.90 & 0.373 & 3.19 \\
\hline $\mathrm{PI} / 0.4 \% \mathrm{~m}-\mathrm{GO}$ & 116.2 & 12.17 & 104.70 & 0.430 & 3.70 \\
\hline $\mathrm{PI} / 0.6 \% \mathrm{~m}-\mathrm{GO}$ & 118.0 & 13.07 & 110.80 & 0.464 & 3.93 \\
\hline
\end{tabular}

$E$ represents compression Young's modulus. $\rho$ represents apparent density of the aerogel. E/ $\rho$ represents specific compression Young's modulus.
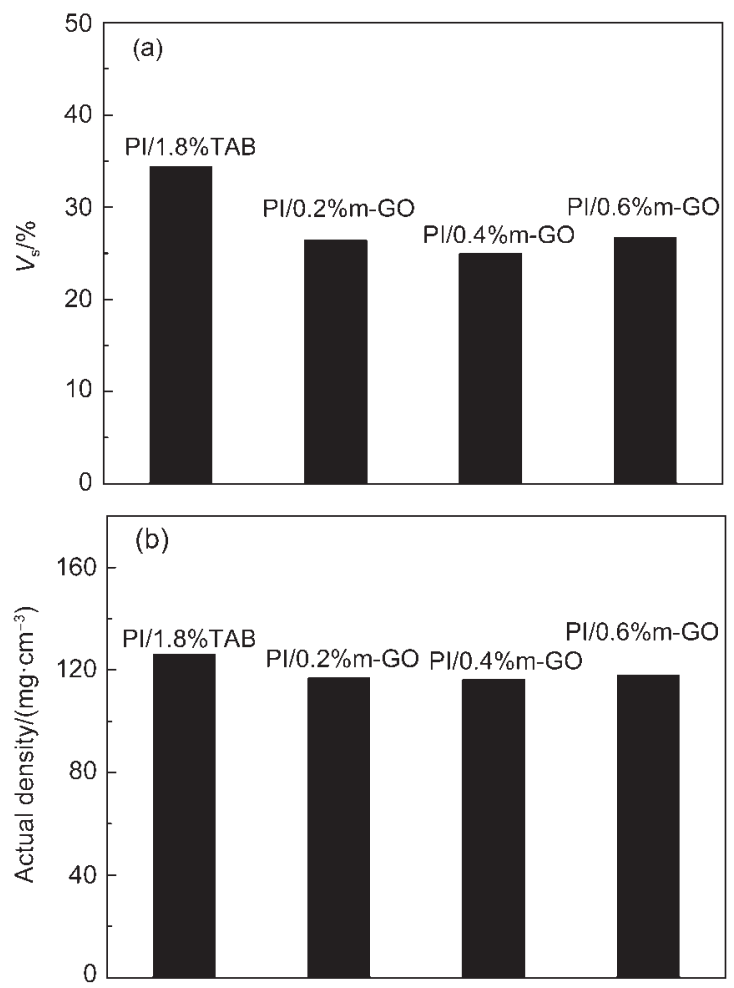

Fig.5 (a) Volume shrinkage ratio and (b) density of the obtained aerogels 


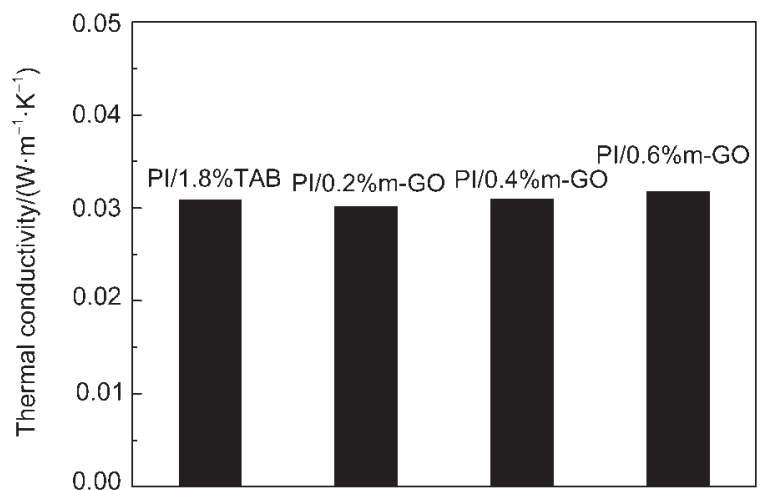

Fig.6 Thermal conductivities of the obtained aerogels

conductivities of the obtained aerogels were measured by hot wire method to investigate the effect of $\mathrm{m}-\mathrm{GO}$ on the aerogels. The thermal conductivities of the $\mathrm{PI} / \mathrm{m}-\mathrm{GO}$ aerogels increased very slightly from 0.0302 to $0.0318 \mathrm{~W} \cdot \mathrm{m}^{-1} \cdot \mathrm{K}^{-1}$ as the $\mathrm{m}-\mathrm{GO}$ content enhanced from $0.2 \%$ to $0.6 \%$, and these values were very close to the thermal conductivity of the PI/1.8\%TAB aerogel (Fig.6). This indicates that the use of $\mathrm{m}-\mathrm{GO}$ as crosslink agent for PI aerogel would not strikingly increase the thermal conductivity, and the PI/ $\mathrm{m}-\mathrm{GO}$ aerogels still remain excellent thermal insulating attribute.

Thermogravimetric (TG) analysis of the composite aerogels shows no surprising results comparing with PI/1.8\%TAB aerogel. As it can be seen in Fig.S6 (Supporting Information), the fast weight loss of all the obtained aerogels took place above the temperature of $520^{\circ} \mathrm{C}$, revealing that the composite aerogels possess excellent thermal stability.

\section{Conclusions}

PI aerogels croslinked with m-GO were prepared by the in-situ polymerization of ODA, BPDA, and m-GO in NMP followed by supercritical $\mathrm{CO}_{2}$ drying. The SEM photos of the PI/m-GO aerogels show that the short fibrous PI aggregates grew on the $\mathrm{m}$ GO sheets, confirming the reaction between m-GO and PI occurred. By crosslinking with only $0.6 \% \mathrm{~m}-\mathrm{GO}$, the superior mechanical properties and less amount of shrinkage in comparison with PI aerogel crosslinked with 1.8\%TAB were achieved, indicating that the $\mathrm{m}-\mathrm{GO}$ has significant reinforcing effect on PI aerogels. Actually, crosslink is critical to improve mechanical property and reduce the shrinkage. In our study, the size of m-GO is much larger than that of the PI aggregates, which may lead to heterogeneity in network and limited crosslinking density. Hence, preparing m-GO with small dimension may be a clue to obtain PI/ $\mathrm{m}$-GO aerogels with more superior properties by conquering the above issues. The results of nitrogen sorption test, TGA, and thermal conductivity measurement reveal that the PI/m-GO aerogels are mesoporous materials with average pore diameters of $12.8-18.3 \mathrm{~nm}$, high specific area of $218.0-259.0 \mathrm{~m}^{2} \cdot \mathrm{g}^{-1}$, and high initial decomposition temperature of about $520^{\circ} \mathrm{C}$, and the reported contents of $\mathrm{m}-\mathrm{GO}$ have no significant effects on the relative properties of the $\mathrm{PI} / \mathrm{m}-\mathrm{GO}$ composite aerogels.
Supporting Information: available free of charge via the internet at http://www.whxb.pku.edu.cn.

\section{References}

(1) Kistler, S. S. Nature 1931, 127, 741.

(2) Tamon, H.; Ishizaka, H.; Mikami, M.; Okazaki, M. Carbon 1997, 35 (6), 791. doi: 10.1016/S0008-6223(97)00024-9

(3) Wang, Z.; Dai, Z.; Wu, J.; Zhao, N.; Xu, J. Adv. Mater. 2013, 25 (32), 4494. doi: 10.1002/adma.v25.32

(4) Xu, Z. J.; Ji, T.; Zhao, L.; Wang, W. Y.; Yang, C. Y.; Gan, L. H. Acta Phys. -Chim. Sin. 2012, 28 (2), 361. [徐子颉, 吉 涛, 赵 蕾, 王玮衍, 杨春艳, 甘礼华. 物理化学学报, 2012, 28 (2), 361.] doi: 10.3866/PKU.WHXB201112063

(5) Guo, X. Z.; Yan, L. Q.; Yang, H.; Li, J.; Li, C. Y.; Cai, X. B. Acta Phys. -Chim. Sin. 2011, 27 (10), 2478. [郭兴忠, 颜立清, 杨 辉, 李 建, 李超宇, 蔡晓波. 物理化学学报, 2011, 27 (10), 2478.] doi: 10.3866/PKU.WHXB20110925

(6) Xu, W. W.; Du, A.; Tang, J.; Chen, K.; Zou, L. P.; Zhang, Z. H.; Shen, J.; Zhou, B. Acta Phys. -Chim. Sin. 2012, 28 (12), 2958. [许维维, 杜 艾, 唐 俊, 陈 珂, 邹丽萍, 张志华, 沈 军, 周 斌. 物理化学学报, 2012, 28 (12), 2958.] doi: 10.3866/PKU. WHXB201209282

(7) Rhine, W.; Wang, J.; Begag, R. Production of Polyimide Aerogel for Carbon Aerogel, Involves Contacting Diamine and Aromatic Dianhydride Monomers in Solvent, Contacting Resulting Poly(amic acid) with Dehydrating Agent, and Drying Resulting Polyimide Gel. U. S. Patent 2004/0132845 A1, 200407-08.

(8) Guo, H.; Meador, M. A. B.; McCorkle, L.; Quade, D. J.; Guo, J.; Hamilton, B.; Cakmak, M.; Sprowl, G. ACS Appl. Mater. Interfaces 2011, 3 (2), 546. doi: 10.1021/am101123h

(9) Guo, H.; Meador, M. A. B.; McCorkle, L.; Quade, D. J.; Guo, J.; Hamilton, B.; Cakmak, M. ACS Appl. Mater. Interfaces 2012, 4 (10), 5422. doi: 10.1021/am301347a

(10) Meador, M. A. B.; Malow, E. J.; Silva, R.; Wright, S.; Quade, D.; Vivod, S. L.; Guo, H.; Guo, J.; Cakmak, M. ACS Appl. Mater. Interfaces 2012, 4 (2), 536. doi: 10.1021/am2014635

(11) Meador, M. A. B.; Wright, S.; Sandberq, A.; Nquyen, B. N.; Vankeuls, F. W.; Mueller, C. H.; Rodríguez-Solís, R.; Miranda, F. A. ACS Appl. Mater. Interfaces 2012, 4 (11), 6346. doi: $10.1021 / \mathrm{am} 301985 \mathrm{~s}$

(12) Novoselov, K. S.; Jiang, D.; Schedin, F.; Booth, T. J.; Khotkevich, V. V.; Morozov, S. V.; Geim, A. K. Proceedings of the National Academy of Sciences 2005, 102 (30), 10451. doi: 10.1073/pnas.0502848102

(13) Mkhoyan, K. A.; Contryman, A. W.; Silcox, J.; Stewart, D. A.; Eda, G.; Mattevi, C.; Miller, S.; Chhowalla, M. Nano Lett. 2009, 9 (3), 1058. doi: 10.1021/n18034256

(14) Shi, H.; Li, Y.; Guo, T. J. Appl. Polym. Sci. 2013, 128 (5), 3163. doi: 10.1002/app.v128.5

(15) Dong, J.; Yin, C.; Zhao, X.; Li, Y.; Zhang, Q. Polymer 2013, 54 
(23), 6415. doi: 10.1016/j.polymer.2013.09.035

(16) Huang, T.; Xin, Y. S.; Li, T. S.; Nutt, S.; Su, C.; Chen, H. M.; Liu, P.; Lai, Z. L. ACS Appl. Mater. Interfaces 2013, 5 (11), 4878. doi: $10.1021 / \mathrm{am} 400635 \mathrm{x}$

(17) Park, O. K.; Hwang, J. Y.; Goh, M.; Lee, J. H.; Ku, B. C.; You, N. H. Macromolecules 2013, 46 (9), 3505. doi: 10.1021/ ma400185j

(18) Liao, W. H.; Yang, S. Y.; Wang, J. Y.; Tien, H. W.; Hsiao, S. T.; Wang, Y. S.; Li, S. M.; Ma, C. C. M.; Wu, Y. F. ACS Appl. Mater. Interfaces 2013, 5 (3), 869. doi: 10.1021/am302494c

(19) Yoonessi, M.; Shi, Y.; Scheiman, D. A.; Lebron-Colon, M.; Tigelaar, D. M.; Weiss, R. A.; Meador, M. A. ACS Nano 2012, 6 (9), 7644.

(20) Zhang, X.; Sui, Z.; Xu, B.; Yue, S.; Luo, Y.; Zhan, W.; Liu, B. J. Mater. Chem. 2011, 21 (18), 6494. doi: 10.1039/c1jm10239g

(21) Ghani, M. A. A.; Abdallah, D.; Kazmaier, P. M.; Keoshkerian, B.; Buncel, E. Can. J. Chem. 2004, 82 (9), 1403. doi: 10.1139/ v04-106

(22) Wang, G. Q. Water Resources Protection 2007, 23 (4), 85. [王 国贤. 水资源保护, 2007, 23 (4), 85. ]

(23) Chen, H.; Yin, J. 1,3,5-Tri (4-amino phenoxy) Benzene and Preparation Method Thereof. CN Patent 1405145 A, 2003-0326. [陈 焕, 印 杰. 1,3,5-三(4-氨基苯氧基)苯及其制备方 法: 中国, CN 1405145 A [P]. 2003-03-26.]

(24) Chidambareswarapattar, C.; Larimore, Z.; Sotiriou-Leventis, C.; Mang, J. T.; Leventis, N. J. Mater. Chem. 2010, 20 (43), 9666. doi: $10.1039 / \mathrm{c} 0 \mathrm{jm} 01844 \mathrm{a}$

(25) Wu, W.; Wang, K.; Zhan, M, S. Ind. Eng. Chem. Res. 2012, 51 (39), 12821. doi: 10.1021/ie301622s

(26) Leventis, N.; Sotiriou-Leventis, C.; Mohite, D. P.; Larimore, Z. J.; Mang, J. T.; Churu, G.; Lu, H. Chem. Mate. 2011, 23 (8), 2250. doi: $10.1021 / \mathrm{cm} 200323 \mathrm{e}$

(27) Yang, S.; Feng, X.; Müllen, K. Adv. Mater. 2011, 23 (31), 3575. doi: 10.1002/adma.201101599 
Supplementary Information for Acta Phys. -Chim. Sin. 2015, 31 (6), 1179-1185 doi: 10.3866/PKU.WHXB201504146

\title{
化学改性氧化石墨烯交联的聚酰亚胺气凝胶
}

\author{
梁祎卢 文武* 姚维尚张学同* \\ (北京理工大学材料科学与工程学院, 北京 100081)
}

\section{Polyimide Aerogels Crosslinked with Chemically Modified Graphene Oxide}

\author{
LIANG Yi LU Yun* YAO Wei-Shang ZHANG Xue-Tong* \\ (School of Materials Science \& Engineering, Beijing Institute of Technology, Beijing 100081, P. R. China)
}

${ }^{*}$ Corresponding authors. LU Yun, Email: luyun@bit.edu.cn.

ZHANG Xue-Tong, Email: zhangxtchina@yahoo.com; Tel: +86-10-68912370. 


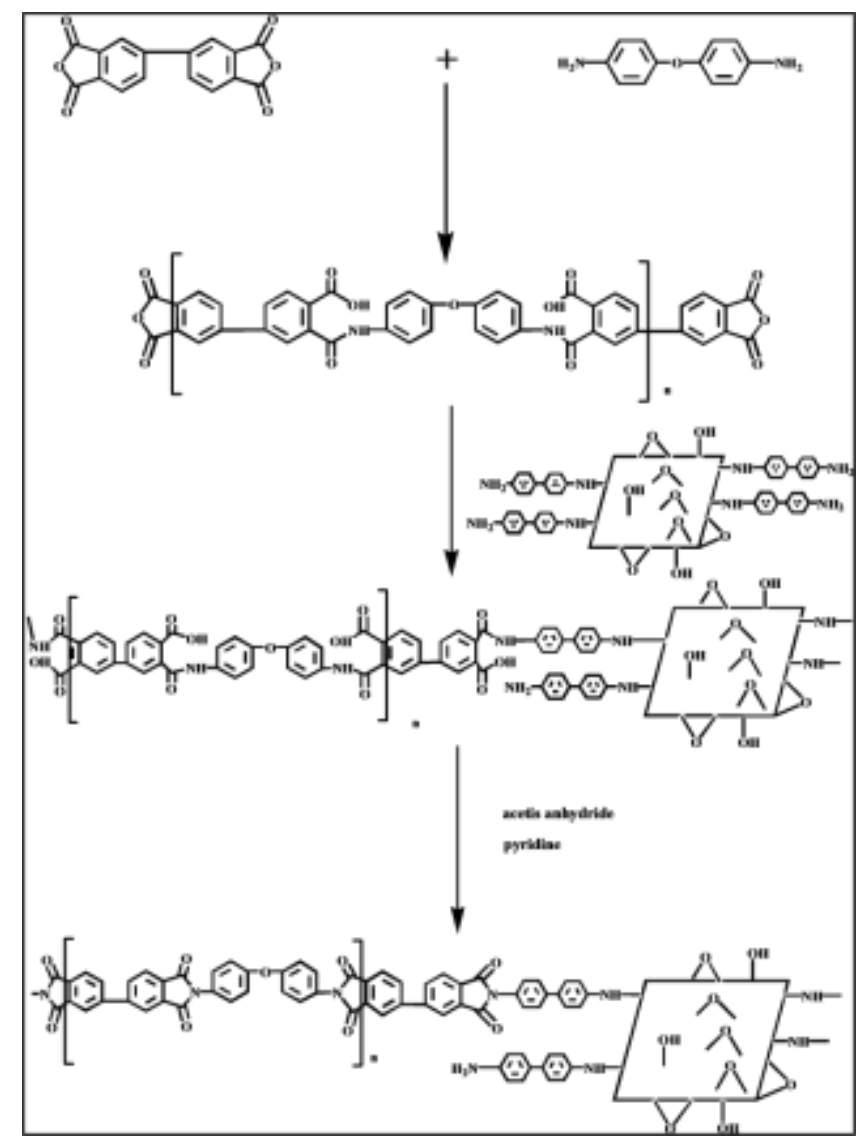

Fig.S1 Sheme of the PI/m-GO aerogels preparation
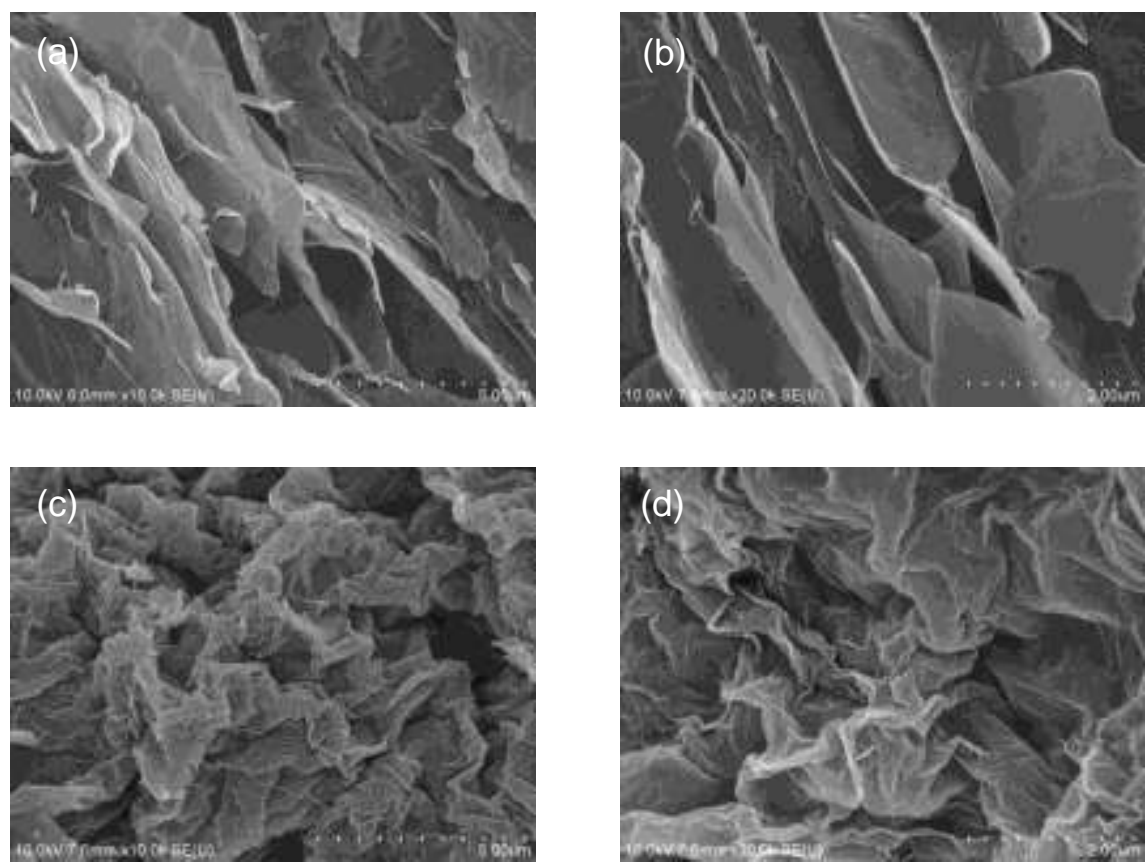

Fig.S2 SEM micrographs of $(a, b)$ GO and $(c, d)$ m-GO 

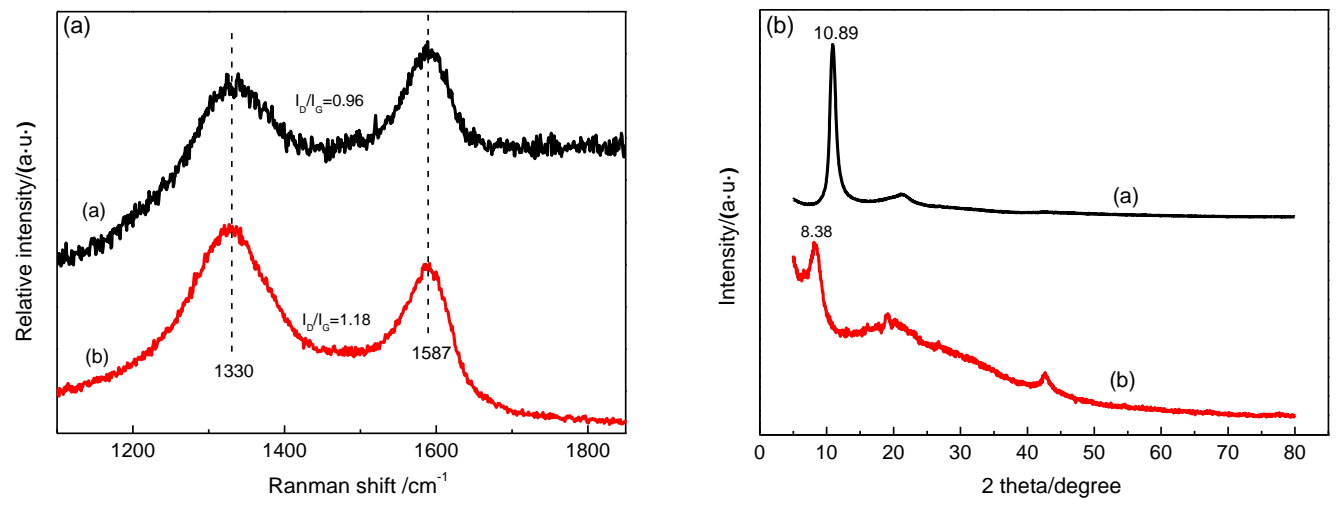

Fig.S3 (a) Raman spectra and (b) XRD pattern of (a) GO and (b) m-GO

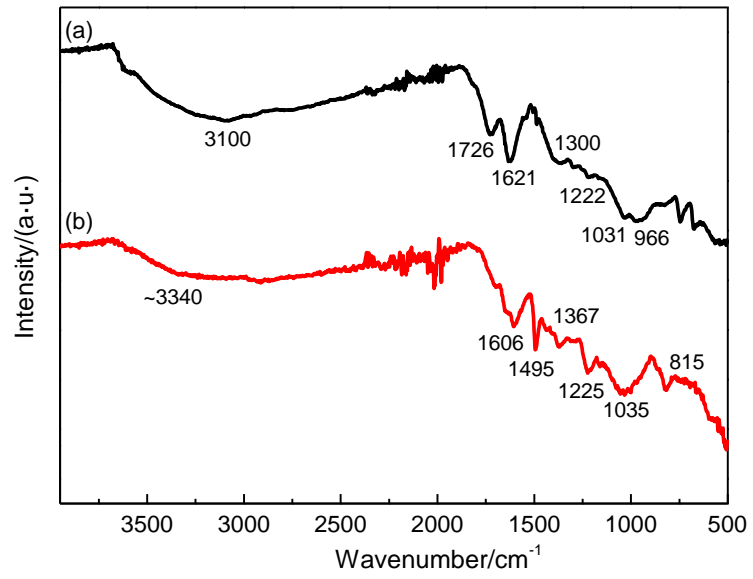

Fig.S4 FTIR spectra of (a) GO and (b) m-GO
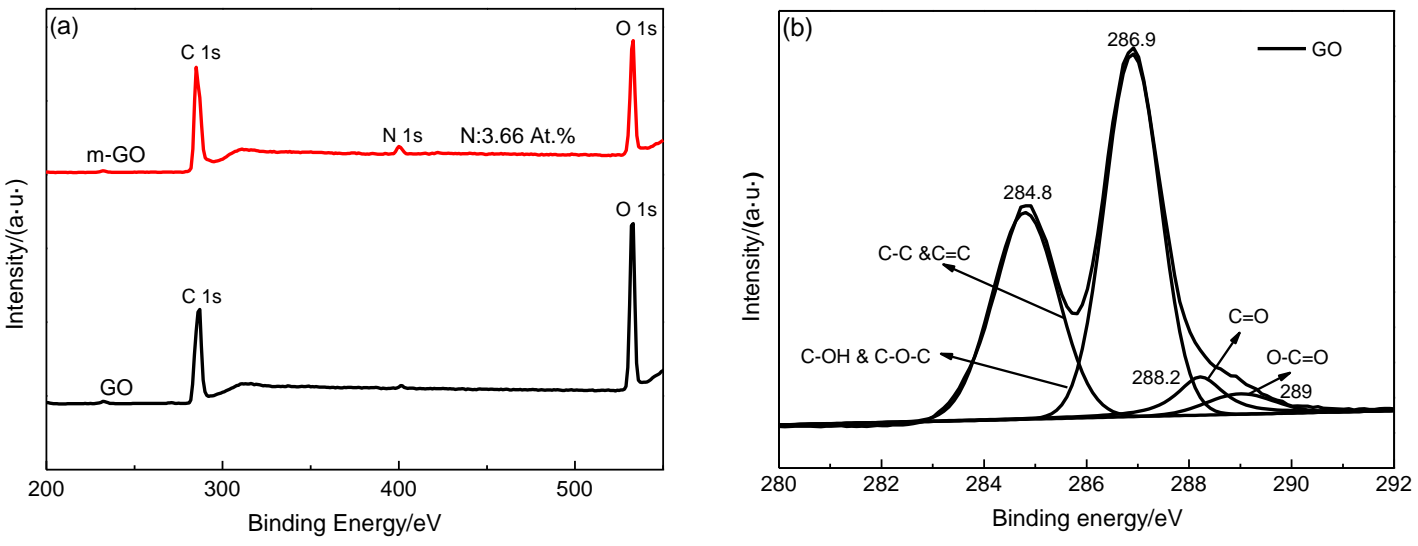

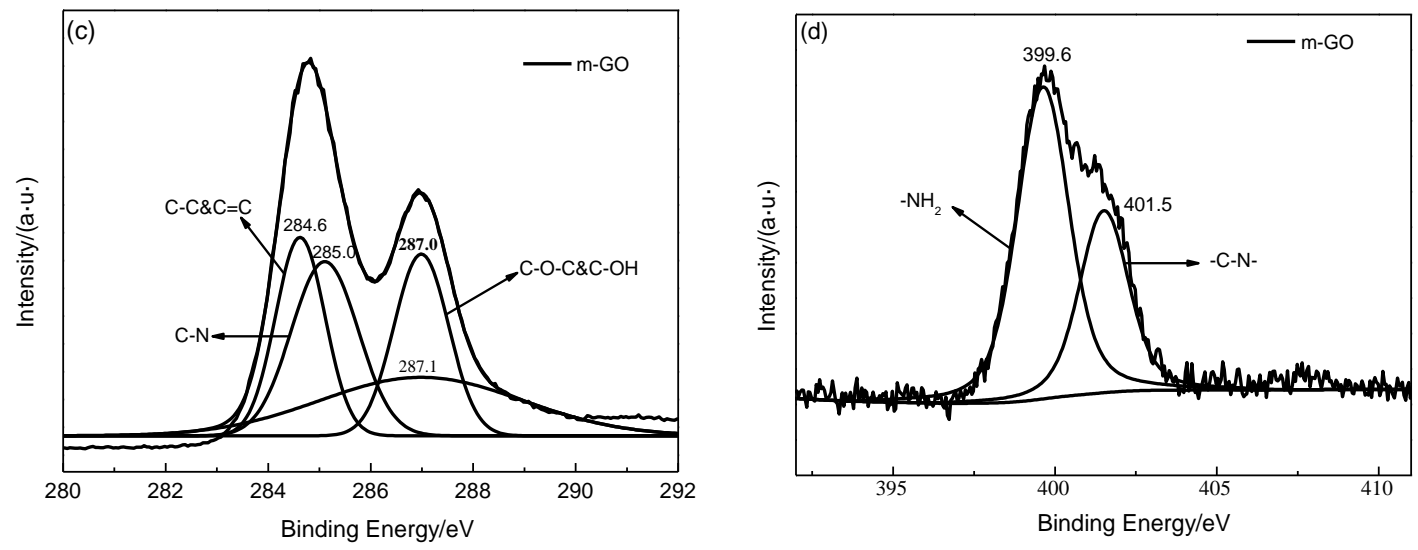

Fig.S5 Survey profiles (a) of m-GO and GO, (b) the C $1 s$ spretrum of GO, (c) the C $1 s$ spretrum of $\mathrm{m}-\mathrm{GO}$ and (d) the $\mathrm{N} 1 s$ spretrum of $\mathrm{m}-\mathrm{GO}$

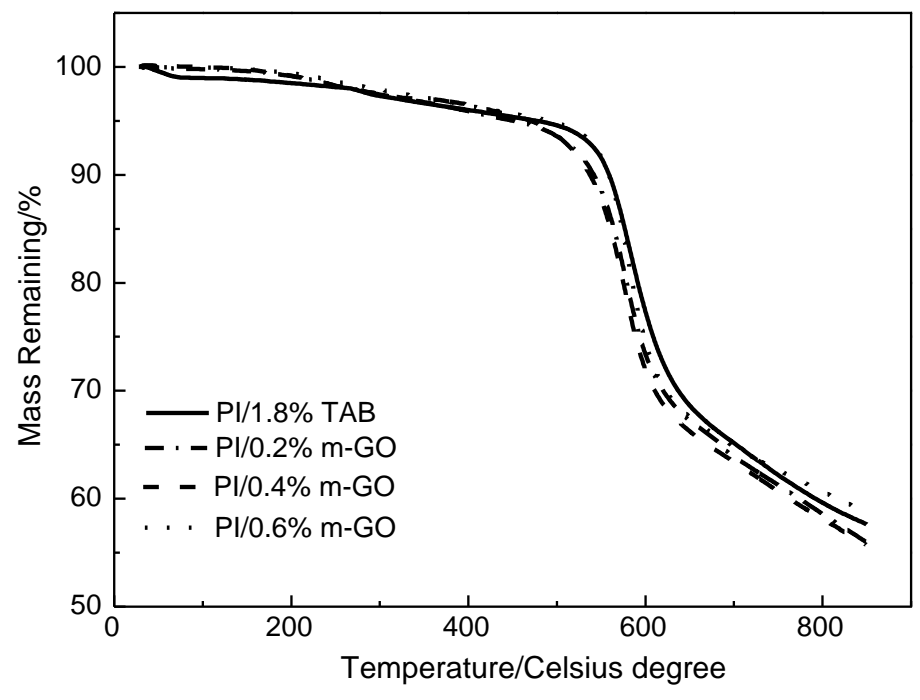

Fig.S6 TG diagrams of the obtained aerogels 